Proc. of the International Conference on Mechanochemistry and Mechanical Alloying, Kraków, Poland, June 22-26, 2014

\title{
Mechanical Activation of Deposited Brown Coal Fly Ash in Stirred Media Mill
}

\author{
Z. MolnáR*, F. KRistály And G. MuCSI \\ University of Miskolc, 3515. Miskolc, Egyetemváros, Hungary
}

\begin{abstract}
Present paper deals with the mechanical activation of deposited brown coal fly ash in a high energy density mill. The mechanical activation was carried out in a laboratory scale stirred media mill using various rotor circumferential speed ( 5 and $7 \mathrm{~m} / \mathrm{s}$ ), and different grinding time (from 1 min up to $180 \mathrm{~min}$ ). The consumed energy was measured during the grinding process. Furthermore, particle size distribution and specific surface area were determined using laser particle size analyzer. The structural changes were detected by Fourier transform infrared spectroscopy. Additionally, transformation in mineralogical phases was measured by X-ray diffraction, as well as particle morphology and crystal defects were determined by transmission electron microscopy. As a result of the investigation, relationship between the technological parameters of the grinding and the properties of the ground material was created. It was found that there is a certain mechanochemical effect on the crystal structure of fly ash components in the stirred media mill, as it was revealed by X-ray diffraction and transmission electron microscopy. The most efficient grinding parameters were determined.
\end{abstract}

DOI: $10.12693 /$ APhysPolA.126.988

PACS: $81.20 . \mathrm{Wk}$

\section{Introduction}

Ultrafine and nanosized powders are commonly used nowadays in the high-tech applications to reach advanced properties [1]. Basically, there are two different approaches in order to produce nanomaterial: one of them is the "top-down" method (for example size reduction by grinding) [2] and the other one is the so called "bottomup" process (from molecular to nanolevel). Stirred ball mills are such machines which are suitable for ultrafineand nanogrinding $[3,4]$. The application of this kind of apparatus becomes widespread in the last decade due to its simple structure and favorable energy demand. Through the high energy density generated in the grinding chamber, extra fine and very reactive final product can be manufactured. These mills are applied in a very wide range: mineral processing, pharmaceutical and food industry and chemical industry.

Several authors investigated the mechanical activation of fly ash [5, 6], but mainly using conventional tumbling ball mill or planetary ball mill (batch mill). Patil and Anandhan [7] and Paul et al. [8] ground fly ash in planetary mill for $60 \mathrm{~h}$. Both papers demonstrate the results of grinding experiments with tungsten carbide grinding balls. Grinding was carried out in wet mode (suspension), surfactant was applied to avoid agglomeration. From the results of X-ray diffraction (XRD), Fourier transform infrared (FT-IR), transmission electron microscopy (TEM) investigation they found that the amorphous phase was increased with $20 \%$ that after $60 \mathrm{~h}$ grinding time, crystallite size reduced and $\mathrm{Si}-\mathrm{OH}$ functional groups formed.

\footnotetext{
*corresponding author; e-mail: molnarz87@gmail.com
}

The aim of our research was to observe the effect of mechanical activation of fly ash in stirred media mill in dry mode under different technological parameters and various residence times and to monitor the grinding kinetics and the material transformation.

\section{Experimental}

\subsection{Materials and methods}

\subsubsection{Characterization of raw fly ash}

Deposited brown coal fly ash collected from Tiszaújváros (Hungary) was used for mechanical activation experiments. The physical and chemical properties of the raw fly ash were determined. Moisture content was 17.3\%. Particle and bulk density was $1.645 \mathrm{~g} / \mathrm{cm}^{3}$ and $0.712 \mathrm{~g} / \mathrm{cm}^{3}$, respectively. Particle size distribution and specific surface area (SSA) was measured by Horiba LA $950 \mathrm{~V} 2$ type laser particle size analyzer. The SSA of raw fly ash was $0.58 \mathrm{~m}^{2} / \mathrm{g}$, while its median particle size was $x_{50}=97.136 \mu \mathrm{m}$. Chemical composition of fly ash (Table) was measured by Rigaku Supermini 200 type X-ray fluorescence spectrometer (XRF). According to the analysis the $\mathrm{SiO}_{2} / \mathrm{Al}_{2} \mathrm{O}_{3}$ ratio was 2.3 , the cumulate $\mathrm{SiO}_{2}$, $\mathrm{Al}_{2} \mathrm{O}_{3}, \mathrm{Fe}_{2} \mathrm{O}_{3}$ content was $92.3 \mathrm{~m} / \mathrm{m} \%$.

TABLE I

Chemical composition of deposited brown coal fly ash from Tiszaújváros. L.O.I. - the loss of ignition.

\begin{tabular}{l|c|c|c|c|c|c|c|c|c}
\hline $\begin{array}{c}\text { Compo- } \\
\text { sition }\end{array}$ & $\mathrm{SiO}_{2}$ & $\mathrm{Al}_{2} \mathrm{O}_{3}$ & $\mathrm{Na}_{2} \mathrm{O}$ & $\mathrm{K}_{2} \mathrm{O}$ & $\mathrm{CaO}$ & $\mathrm{MgO}$ & $\mathrm{Fe}_{2} \mathrm{O}_{3}$ & $\mathrm{SO}_{3}$ & L.O.I. \\
\hline wt.\% & 61.32 & 26.71 & 1.06 & 1.72 & 1.50 & 0.89 & 4.27 & 0.25 & 1.92 \\
\hline
\end{tabular}

The mineralogical composition of fly ash was investigated by X-ray powder diffraction (XRD). We found that 
beside $73 \mathrm{~m} / \mathrm{m} \%$ amorphous content, the main mineral phases were quartz, mullite and cristobalite.

\subsubsection{Mechanical activation in stirred media mill}

The applied mill was developed by the Institute of Raw Material Preparation and Environmental Processing. Mill was equipped with ceramic liners and discs to reach high wear resistance. Five discs were fixed on the driven axis. Cooling system of the mill consists of a cooling jacket which was connected to water supply. Effective volume of the mill is $530 \mathrm{~cm}^{3}$, the used filling ratio of grinding beads $(\varnothing 0.8-1.0 \mathrm{~mm}$ Zirconia balls coated with Yttrium) was $60 \%$. The material filling ratio was $50 \%$. Control of the rotor speed ( 5 and $7 \mathrm{~m} / \mathrm{s}$ ) was realized with a frequency control unit. The consumed energy was measured with a Carlo Gavazzi 70 type digital energy meter. The residence time was $1,3,5,10,15,30,60$, 120 , and $180 \mathrm{~min}$.

\subsubsection{Laser particle size analyzer}

The particle size distribution of the ground products had been investigated using a Horiba LA-950 V2 type laser particle size analyzer (LPSA). Specific surface area had been calculated from the distribution data, shape factor was 1.0. To achieve an appropriate disperse state one minute ultrasonic dispersing and $0.5 \mathrm{ml}$ sodium pyrophosphate dispersant was applied.

\subsubsection{FTIR investigations}

Investigation was carried out using a JASCO FT-IR 4200 type Fourier transform infrared spectrometer, in transmission mode, on $\mathrm{KBr}$ cemented pellets. One spectrum was the average of $32 \mathrm{FT}$-IR measurements with $4 \mathrm{~cm}^{-1}$ resolution number.

\subsubsection{X-ray powder diffraction}

XRD investigations were carried out on a Bruker D8 Advance diffractometer $\left(\mathrm{Cu} K_{\alpha}\right.$ radiation, $40 \mathrm{kV}$, $40 \mathrm{~mA}$ ). Crystalline components were identified by Search/Match algorithm in Bruker DiffracPlus EVA software package using ICDD PDF-2 (2005) database. Quantitative results were obtained by Rietveld-refinement, in Bruker TOPAS4 software using ICSD database.

\subsubsection{Transmission electron microscopy}

The samples were studied with a FEI Tecnai G2 transmission electron microscope (equipped with EDAX energy dispersive X-ray spectrometer). The acceleration voltage was $200 \mathrm{kV}$. Electron diffraction patterns, bright field images, high resolution TEM (HRTEM) images, EDX spectra and STEM images were taken for characterizing the shape of the grains and the textural relation of the amorphous and crystalline parts.

\section{Results}

\subsection{Grinding kinetics}

The stress intensity (SI) of the stirred media milling was determined according to Kwade \& Schwedes [9] and Kwade [10]. There is a correlation between the energy input and the energy of the grinding media. The stress intensity can be calculated with the following equation:
$\mathrm{SI} \propto \mathrm{SI}_{\mathrm{GM}}=d_{\mathrm{GM}}^{3} \cdot \rho_{\mathrm{GM}} v_{t}^{2}$, where: $\mathrm{SI}_{\mathrm{GM}}$ - stress intensity of grinding media $[\mathrm{Nm}]$, $d_{G M}$ - diameter of the grinding media $[\mathrm{m}], \rho_{G M}-$ density of grinding media $\left[\mathrm{kg} / \mathrm{m}^{3}\right]$. The energy utilization $\left(\mathrm{EU}, \mathrm{m}^{2} / \mathrm{kJ}\right)$ represents the specific surface area produced by one unit of grinding work which was calculated using the following equation:

$$
\mathrm{EU}=\frac{S_{\text {grind }}-S_{0}}{W_{\mathrm{g}}},
$$

in which $S_{\text {grind }}$ is the SSA of the ground material $\left[\mathrm{m}^{2} / \mathrm{kg}\right.$, $S_{0}$ is the initial SSA of the raw fly ash $\left[\mathrm{m}^{2} / \mathrm{kg}\right]$ and $W_{\mathrm{g}}$ is the specific grinding work $[\mathrm{kJ} / \mathrm{kg}]$. We found that the relationship of specific grinding energy and grinding time can be described using linear curve in the applied time interval

The variation of the product fineness (SSA, median particle size and $80 \%$ passing size) as function of grinding energy can be seen in Figs. 1 and 2 .

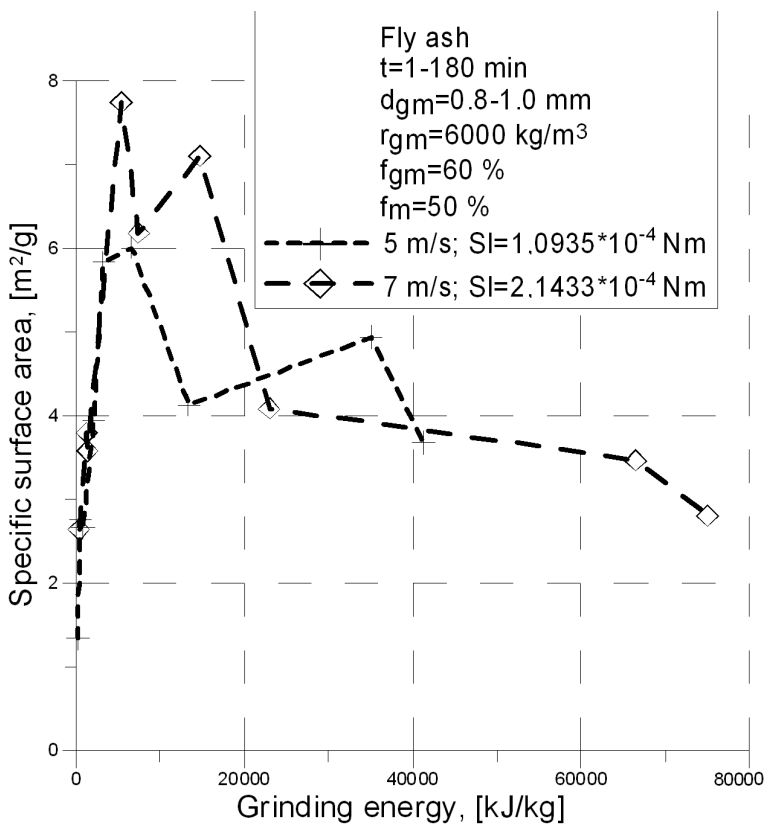

Fig. 1. Variation of specific surface area as function of grinding energy with different circumferential speed.

Increasing specific grinding energy resulted in finer product, especially in the beginning stage of the grinding process. The median particle size $\left(x_{50}\right)$ decreased from $97.14 \mu \mathrm{m}$ down to $1.21 \mu \mathrm{m}\left(v_{\text {cir }}=5 \mathrm{~m} / \mathrm{s}\right)$ and $0.80 \mu \mathrm{m}$ $\left(v_{\text {cir }}=7 \mathrm{~m} / \mathrm{s}\right)$ in a relatively short period of time (after $10 \mathrm{~min}$ ), which were the minimum values (Fig. 2). After that point the median and $x_{80} \%$ particle size were almost constant in the case of $5 \mathrm{~m} / \mathrm{s}$ circumferential speed and started to be increased in $7 \mathrm{~m} / \mathrm{s}$ (aggregation appears). The maximum specific surface area $\left(6.01 \mathrm{~m}^{2} / \mathrm{g}\right)$ reached at $6613.95 \mathrm{~kJ} / \mathrm{kg}$ (30 min grinding time) energy input in case of $5 \mathrm{~m} / \mathrm{s}$ rotor circumferential speed, and $7.78 \mathrm{~m}^{2} / \mathrm{g}$ at $5358.14 \mathrm{~kJ} / \mathrm{kg}$ (after 10 min grinding) energy input in case of $7 \mathrm{~m} / \mathrm{s}$ case (Fig. 1). The higher circumferential 


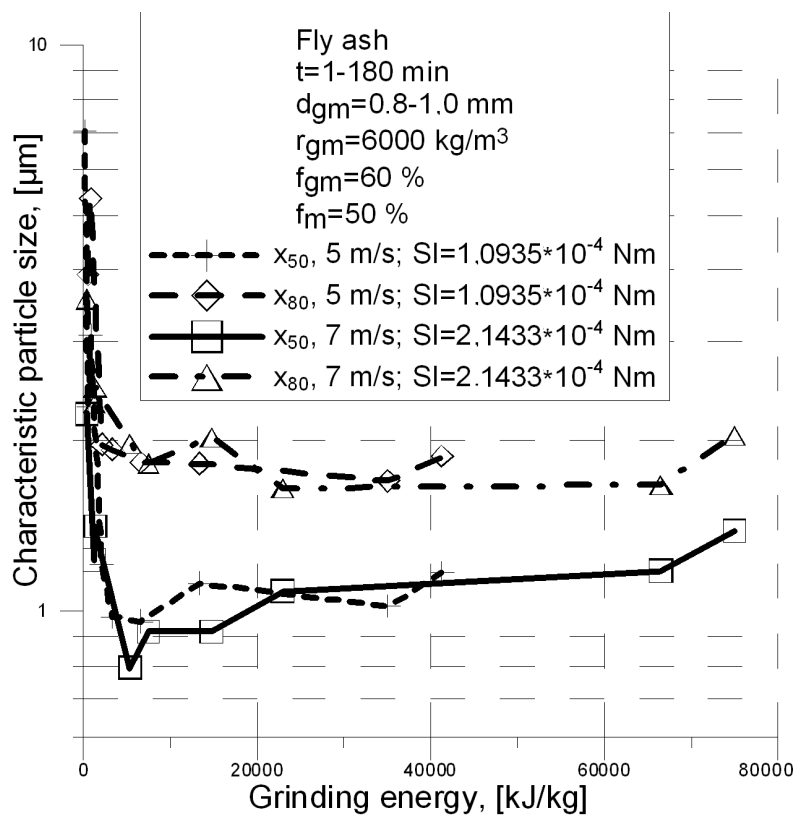

Fig. 2. Variation of characteristic particle size as function of grinding energy with different circumferential speed.

speed resulted in much higher specific surface area with less energy input. However, the difference was smaller in characteristic particle sizes $\left(x_{50}, x_{80}\right)$.

Frequency distribution curves of the ground materials can be seen in Figs. 3 and 4 for 5 and $7 \mathrm{~m} / \mathrm{s}$ circumferential speed, respectively. The variation of the modality at different circumferential speed was diverse. The distribution of the raw fly ash was monomodal.

In the case of $5 \mathrm{~m} / \mathrm{s}$ circumferential speed after $1 \mathrm{~min}$ grinding time the curve became trimodal (Fig. 3), after 3 min the coarser mode (which was preliminary in the range of 30-200 $\mathrm{mm}$ ) disappeared, the curve became bimodal, and the amount of very fine $(0.08-1 \mu \mathrm{m})$ particles increased. For further grinding, particles between $0.2-5 \mu \mathrm{m}$ appeared and later its amount increased significantly. At the same time the particles in the size fraction of $0.08-1 \mu \mathrm{m}$ were aggregated.

The circumferential speed of $7 \mathrm{~m} / \mathrm{s}$ the curve was bimodal after $1 \mathrm{~min}$, then after $3 \mathrm{~min}$ it became trimodal (Fig. 4). The coarse particles (10-100 $\mu \mathrm{m}$ ) appeared due to the aggregation of fine particles, which were not detected after 1 min grinding time. After $10 \mathrm{~min}$ the curve remained bimodal, but distribution became finer, extra fine particles $(0.08-0.8 \mu \mathrm{m})$ present in the highest amount. After it a strong aggregation was observed, the curve was monomodal again (60 and $120 \mathrm{~min}$ ) the particle size range became much narrower. In the case of 180 min grinding product the distribution was coarser, particles of 10-100 $\mu \mathrm{m}$ appeared again, the distribution was bimodal again.

It can be stated from Fig. 5 that the energy utilization decreased as function of grinding time in both cases.

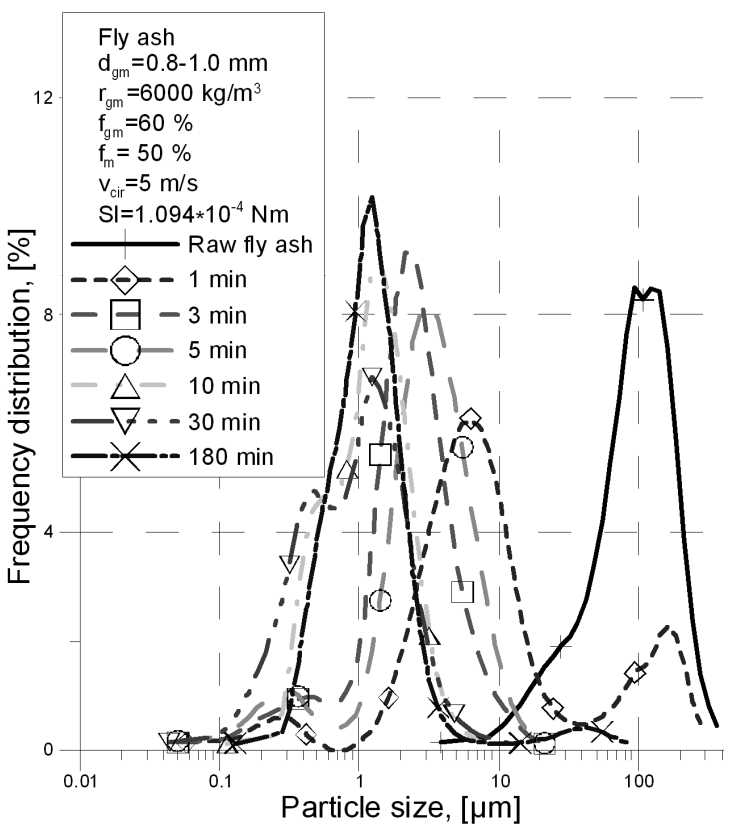

Fig. 3. Mass ratio of the ground material at different grinding times $\left(v_{\text {cir }}=5 \mathrm{~m} / \mathrm{s}\right)$.

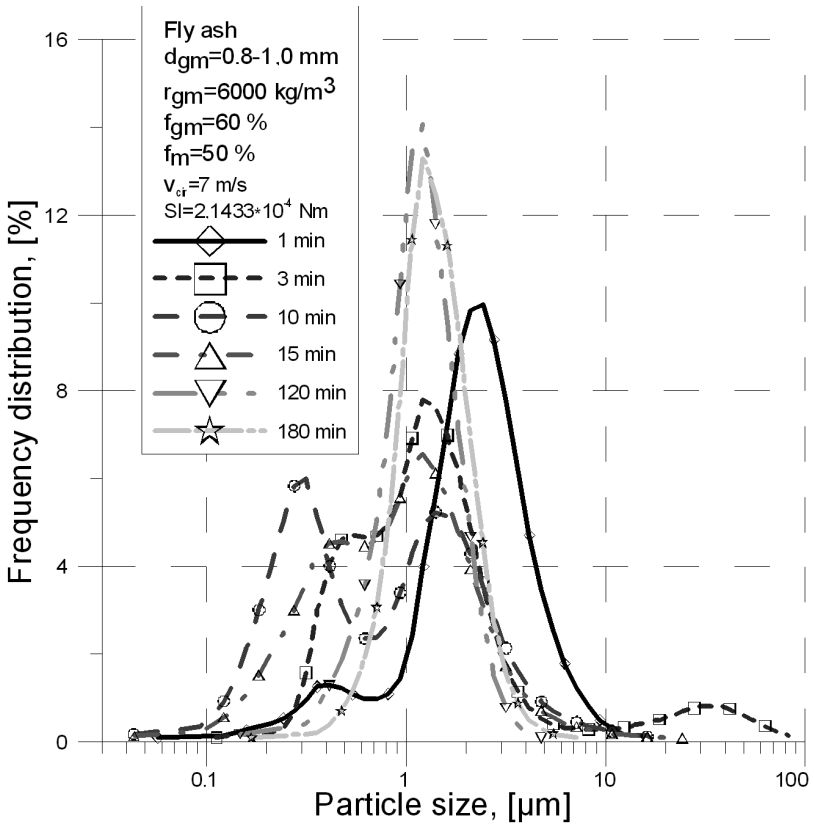

Fig. 4. Mass ratio of the ground material at different grinding times $\left(v_{\text {cir }}=7 \mathrm{~m} / \mathrm{s}\right)$.

Power function can be fitted to the measured points whose equations are as follows: for $5 \mathrm{~m} / \mathrm{s}$ :

$$
\ln (\mathrm{EU})=-0.90 \ln (t)+2.55 \text {, }
$$

for $7 \mathrm{~m} / \mathrm{s}$ :

$$
\ln (\mathrm{EU})=-1.05 \ln (t)+2.45
$$

with R-squared 0.96 and 0.97 for 5 and $7 \mathrm{~m} / \mathrm{s}$, respectively. 


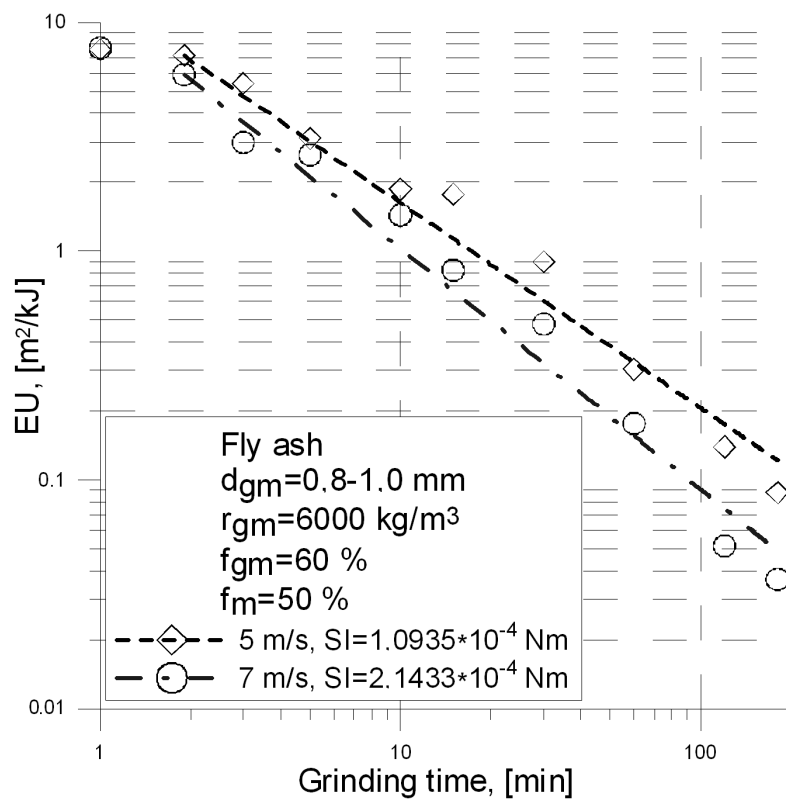

Fig. 5. Changes in Energy Utilization (EU) as function of grinding time.

\subsection{FT-IR}

Based on the raw and stirred ball milled fly ash FT-IR spectra (Figs. 6 and 7) significant absorbance can be observed at 3445 and $1630 \mathrm{~cm}^{-1}$ corresponds to $-\mathrm{OH}, \mathrm{HOH}$ stretching and $\mathrm{HOH}$ bending vibration. Between these wave numbers no significant absorbance was found. The $1420 \mathrm{~cm}^{-1}$ corresponds to stretching vibration of $\mathrm{O}-\mathrm{C}-\mathrm{O}$ bonds, presumably related to the presence of carbonate, these peaks did not appear in all cases. 1070-1100, 795, and $560 \mathrm{~cm}^{-1}$ peaks related to $\mathrm{T}-\mathrm{O}-\mathrm{Si}(\mathrm{T}=\mathrm{Si}$, or $\mathrm{Al})$ bonds asymmetric and symmetric stretching vibration. In the case of raw fly ash, peak at $1067 \mathrm{~cm}^{-1}$ shifted to higher wave number due to grinding. Peak belongs to $467 \mathrm{~cm}^{-1}$, related to bending vibration of $\mathrm{Si}-\mathrm{O}-\mathrm{Si}$ and $\mathrm{O}-\mathrm{Si}-\mathrm{O}$. The $60 \mathrm{~min}(5 \mathrm{~m} / \mathrm{s})$ ground fly ash shows the most differences compared to other spectra. In this case the peak at $874 \mathrm{~cm}^{-1}$ corresponds to $\mathrm{Si}-\mathrm{O}$ stretching, $\mathrm{OH}$ bending vibrations of $\mathrm{Si}-\mathrm{OH}$ bonds. It is due to $\mathrm{SiO}_{2}$ domains were broken down during the milling according to Paul et al. (2007) and parallel Si-OH was formed proved structural changes due to the milling.

Comparing the spectra at the same grinding time and various circumferential speeds significant differences were not observed.

\subsection{XRD}

The main component of fly ash is amorphous (glasslike) material. Mineral phases of fly ash are mullite, quartz, cristobalite, and magnesioferrite minor phases as sillimanite, bytownite also appeared. Mullite was identified in two varieties, according to Al-Si ratio in the chemical composition. The magnesioferrite structure was used

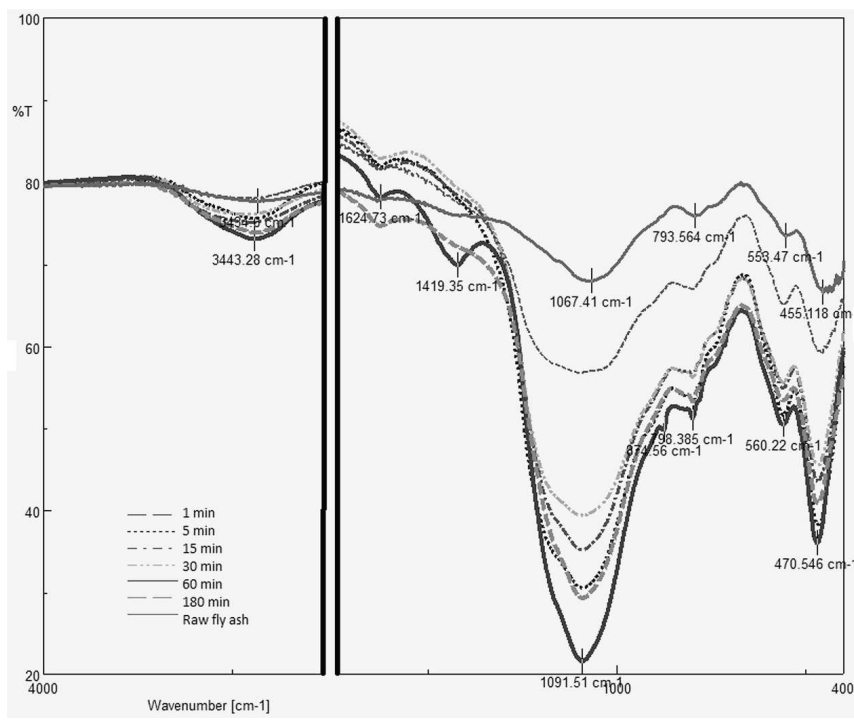

Fig. 6. FT-IR spectra of ground fly ash $\left(v_{\text {cir }}=5 \mathrm{~m} / \mathrm{s}\right)$.

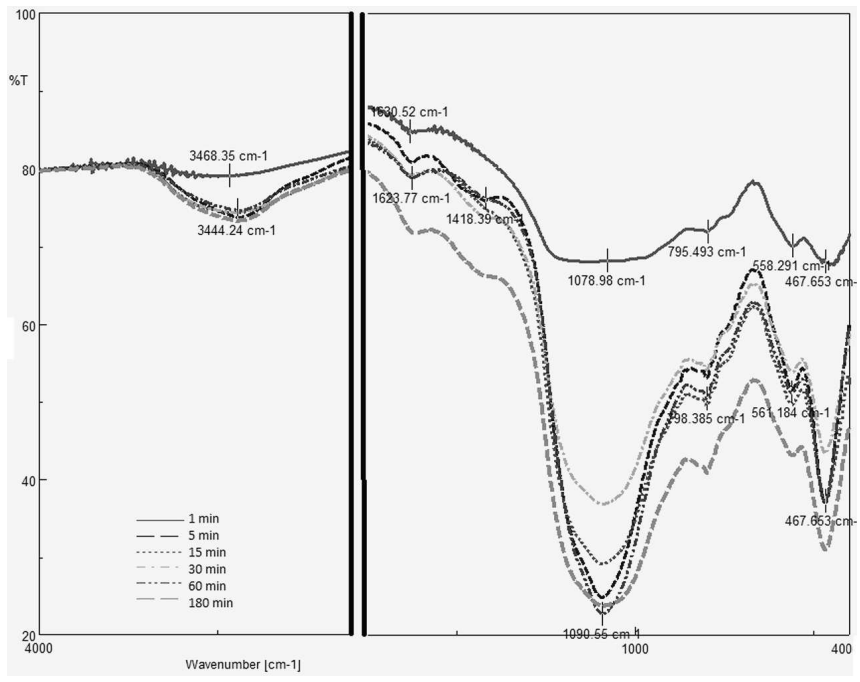

Fig. 7. FT-IR spectra of ground fly ash $\left(v_{\text {cir }}=7 \mathrm{~m} / \mathrm{s}\right)$.

to quantify the spinel-type oxides, since the peak broadening and overlapping with mullite peaks ( $2 \theta$ is mainly $\approx 35^{\circ}$ ) made impossible the detailed identification of the similar spinel phases. The main changes in crystalline phases belong to the shift from 2:1 mullite to 3:2 type mullite.

In Figs. 8 and 9 the changes of mullite amount can be seen for 2:1 and 3:2 types, as function of grinding energy. As function of grinding energy the amount of mullite $2: 1$ decreased, parallel to mullite $3: 2$ increased at 5 and $7 \mathrm{~m} / \mathrm{s}$ as well. The changes in phase took place due to mechanical energy, like pressure increase at ball impact. Heat generation in the mill chamber was significant; the maximum temperature exceeded $160^{\circ} \mathrm{C}$ during the grinding process. However, this temperature is not high enough to result in thermo-chemical or structural changes in the 


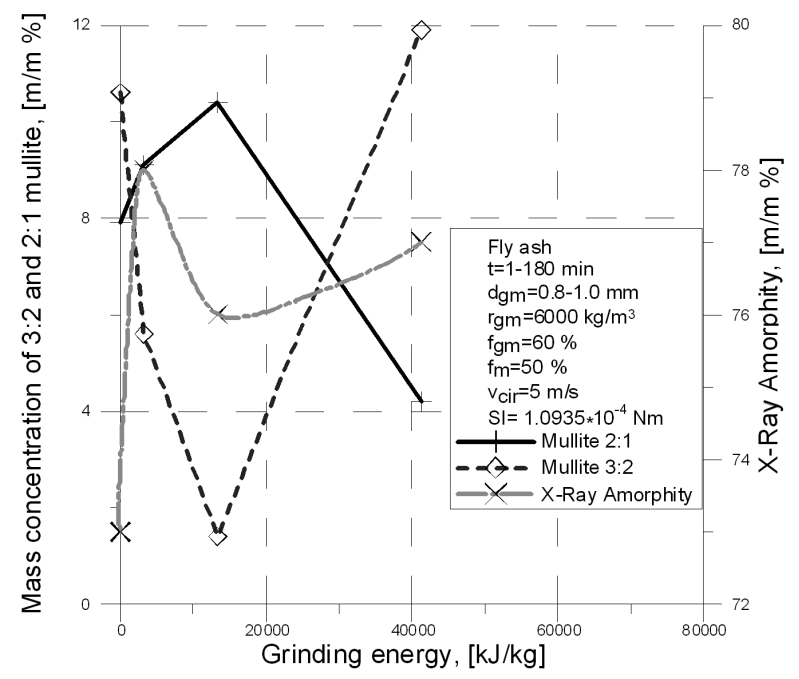

Fig. 8. Changes of mass concentration of mullite varieties and amorphous content $\left(v_{\text {cir }}=5 \mathrm{~m} / \mathrm{s}\right)$.

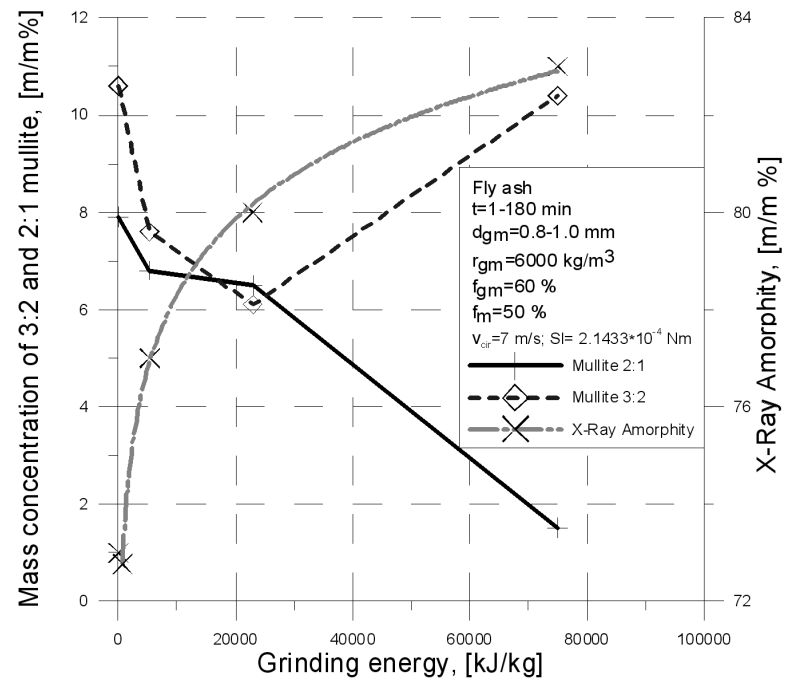

Fig. 9. Changes of mass concentration of mullite varieties and amorphous content $(v=7 \mathrm{~m} / \mathrm{s})$.

above mentioned minerals, so the above transformation happened due to the mechanical activation.

The variation of the amorphous content from XRD measurements as function of grinding energy is also shown in Figs. 8 and 9. The amorphous content of the raw fly ash was $73 \%$. Increasing grinding time resulted in the increase of amorphous content, but with different intensity in the case of various circumferential speeds. Grinding with $5 \mathrm{~m} / \mathrm{s}$ resulted in $5 \%$ maximum increase in amorphous content, after $15 \mathrm{~min}$ it was $78 \%$, while after 60 and 180 min remained constant ( 76 and $78 \%$ ). In case of $7 \mathrm{~m} / \mathrm{s}$ circumferential speed after 10,60, and $180 \mathrm{~min}$ the amorphous content changed to 77,80 , and $83 \%$ respectively. It can be concluded that amorphisation was more significant at higher rotor speed which is related to the higher stress intensity. Power function can be fitted to measured points in case of $7 \mathrm{~m} / \mathrm{s}$ circumferential speed $(\mathrm{R}$-squared $=0.998)$, with the following equation:

$$
\ln (A)=0.028 \ln (E)+4.10 \text {. }
$$

\subsection{TEM}

In most of the TEM images the diffraction images were added to the bottom corner of Fig. 10. In diffraction image the diffuse rings show the amorphous parts of the particles, while discrete reflections originated from crystalline phases, mainly form mullite. Morphology of particles is also observable. Raw fly ash has reticular morphology (see Fig. 10a). After 5 min of grinding the particles mainly have angular shape, after $60 \mathrm{~min}$ the shape becomes more spherical (Fig. 10d), after $180 \mathrm{~min}$ it was rather spherical (Fig. 10f).
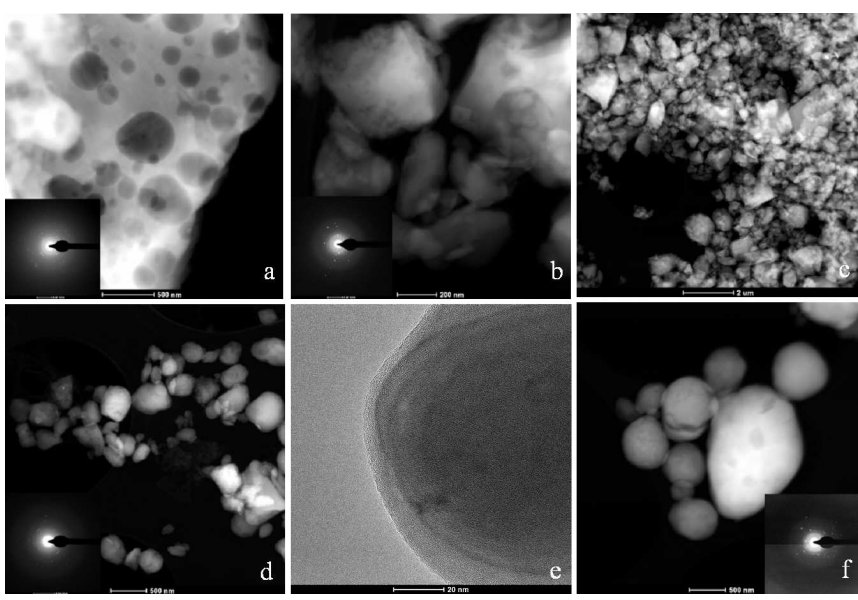

Fig. 10. TEM images of raw and ground fly ash $\left(v_{\text {cir }}=7 \mathrm{~m} / \mathrm{s}\right.$ ); (a) Raw fly ash, (b) 5 min ground fly ash,(c) 5 min ground fly ash, (d) 60 min ground fly ash, (e) 60 min ground fly ash, (f) 180 min ground fly ash.

Based on the TEM images it can be stated that most particles are amorphous, which contain crystalline phases, mainly mullite. In Fig. 10e a crystalline particle is shown, coated with an amorphous layer (5-15 nm thickness). Since this appeared after 60 min grinding time, it was expected to be generated by the mechanical activation process.

\section{Conclusions}

Based on the results the following conclusions can be drawn. The finest fly ash product was reached at $7 \mathrm{~m} / \mathrm{s}$ circumferential speed $\left(\mathrm{SI}=2.1433 \times 10^{-4} \mathrm{~N} \mathrm{~m}\right)$ for $10 \mathrm{~min}$ $\left(\mathrm{SSA}=7.763 \mathrm{~m}^{2} / \mathrm{g} ; x_{50}=0.8 \mu \mathrm{m} ; x_{80}=1.98 \mu \mathrm{m}\right)$.

The amount of mullite $2: 1$ decreased, paralell to mullite $3: 2$ increased at 5 and $7 \mathrm{~m} / \mathrm{s}$ as function of grinding energy. Increasing grinding time X-ray amorphicity increased, but with different rate in case of different circumferential speed. 
According to TEM investigation, raw fly ash particles have reticular morphology. With increasing milling time, particle shape become rounded at the submicron size range. Most particles are amorphous, which contain crystalline phases, mainly mullite.

\section{Acknowledgments}

This work was carried out as part of the IndoHungarian TéT project entitled "Tailoring of geopolymer properties by mechanical activation" (GEOPOL10). Authors appreciate for implementation and helping in evaluation in TEM investigations for Mr. Péter Pekker and Ms. Ildikó Cora, MTA-ME Materials Science Research Group.

\section{References}

[1] T. Pradeep, Nano Essentials, Understanding the Nanoscience and Nanotechnology, Tata McGraw-Hill, New Delhi 2007.
[2] L. Tilstra, S.A. Broughton, R.S. Tanke, D. Jelski, V. French, G. Zhang, A.K. Popov, A.B. Western, T.F. George, The Science of Nanotechnology: An Introductory Text,Nova Science, New York 2008.

[3] H. Choi, W. Lee, S. Kim, Adv. Powder Technol. 20, 350 (2009).

[4] Á. Rácz, Építóanyag 62, 46 (2010).

[5] S. Kumar, R. Kumar, Ceram. Int. 37, 533 (2011).

[6] J. Temuujin, R.P. Williams, A. van Riessen, J. Mater. Process. Tech. 209, 5276 (2009).

[7] A.G. Patil, S. Anandhan, Int. J. Energy Eng 2, 57 (2012).

[8] K.T. Paul, S.K. Satpathy, I. Manna, K.K. Chakraborty, G.B. Nando, Nanoscale Res. Lett. 2, 397 (2007).

[9] A. Kwade, J. Schwedes, Powder Technol. 122, 109 (2002).

[10] A. Kwade, Int. J. Miner. Process. 74, S93 (2004). 